\title{
FORAGING DISTRIBUTION OF AN ANTARCTIC SOUTHERN GIANT PETREL POPULATION
}

\author{
http://dx.doi.org/10.4322/apa.2014.069
}

\author{
Maria Virginia Petry ${ }^{1, *}$, Lucas Krüger ${ }^{1}$
}

\begin{abstract}
${ }^{1}$ Laboratório de Ornitologia e Animais Marinhos, Universidade do Vale do Rio dos Sinos - UNISINOS,
\end{abstract}
Av. Unisinos, 950, Cristo Rei, CEP 93022-000, São Leopoldo, RS, Brazil

*e-mail: vpetry@unisinos.br

Abstract: We present preliminary results on the foraging distribution of Southern Giant Petrels tagged with geolocators in Stinker Point, Elephant Island. Our results showed that Giant Petrels range over a large area from the Antarctic Peninsula until Southern South America, and there is notable segregation between male and female. Females tend to use the area they are distributed equally, while males remain more often close to colonies, but the latitudes and longitudes they used in general were the same. That is quite different from literature, which indicate that Giant Petrel genders use distinct foraging areas, at least South American populations. Further results from the study are underway and we expect to add environmental variables to evaluate differences between genders and try to explain their movements.

Keywords: breeding period, foraging ecology, gender differences, geolocation

\section{Introduction}

Seabirds rely almost exclusively on the sea. They are bonded to land only for reproduction, and even then, the resources necessary to raise a brood are from off shore. Factors influencing on land such as severe weather, gusty winds, hazardous blizzards can reduce adult survival and breeding success (Mallory et al., 2009), but the main factors driving seabird population dynamics are the oceanic factors (Sandvik et al., 2008; Rolland et al., 2010).

Biotic and abiotic factors are used by seabirds for guidance when searching for food, such as productivity, sea and wind currents, temperature, and so on (Adams \& Flora, 2010; Copello et al., 2011). Nonetheless, long time changes in such factors can affect adult survival and breeding success (Rolland et al., 2010).

Hence, this paper presents preliminary results on a study conducted with geolocators on an Antarctic population of Southern Giant Petrels, aiming to obtain data on sea distribution and sea use while foraging.

\section{Materials and Methods}

Study was conducted on Stinker Point $\left(61^{\circ} 07^{\prime} 31^{\prime \prime} \mathrm{S}\right.$ and $\left.55^{\circ} 19^{\prime} 26^{\prime \prime} \mathrm{W}\right)$, Elephant Island, recently presented as
Antarctic IBA 072 (Harris et al., 2011). Stinker Point is the northernmost island of the South Shetlands, and provides a breeding ground for several seabird and seamammal species. The Southern Giant Petrel SGP is one of the most numerous seabirds in the area. The SGPs breed on elevated and relatively plain terrains among 30 and $60 \mathrm{~m}$ above sealevel.

We deployed on 11/11/2011 (period of egg laying), 12 Lotek LAT 2009 Avian FlatpackGeolocators in males and females SGPs from different nests. We attached the tags made of aluminum bands with small plastic seals. The tags were recovered from birds in periods between seven and fourteen days after deployment, the data was downloaded and then redeployed in other SGPs.

The tags generated daily average geographic positions based on light intensity and hour of sunrise and sunset. Positions were filtered by generating a threshold circle with 2 standard deviation position with ArcGis. All points that fell out of the threshold line were excluded. We calculated Kernel density to estimate the most frequently used areas by those individuals. We compared Latitude and Longitude between genders and in different months (November, 


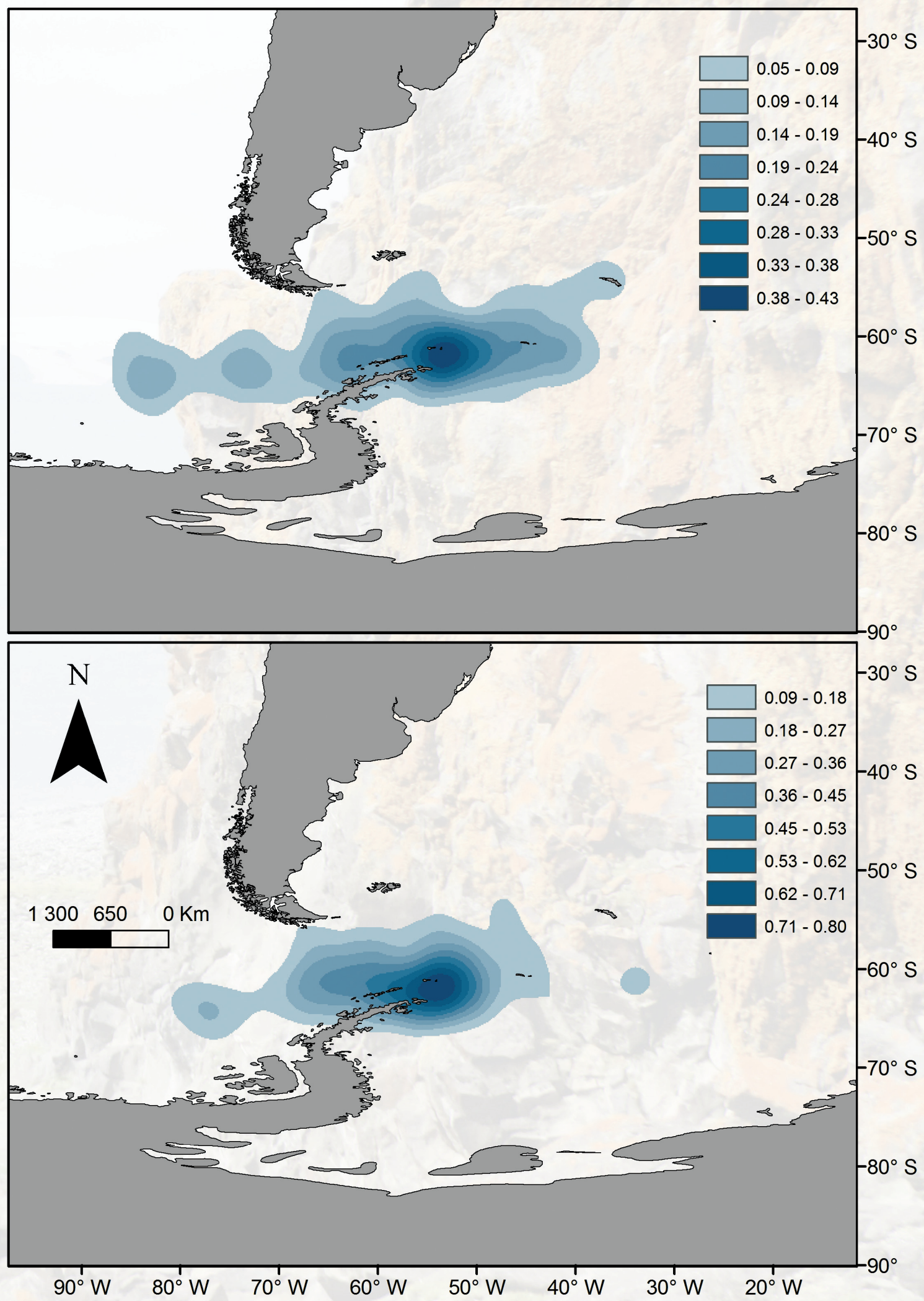

Figure 1. Kernel density for Females (above) and Males (below) Southern Giant Petrels. Frequency is expressed in terms of proportion. 
December and January) with a Repeated Measures ANOVA to detect differences in areas used by genders.

\section{Results}

We were able to monitor 18 SGPs (7 males and 11 females) during all the breeding period. The filtering resulted in a total of 178 points entering the analysis. From a first visual inspection of the Kernel Density distribution, both males and females used similar areas, comprising the Antarctic Peninsula until Southern South-America (Tierra del Fuego, near $55^{\circ} \mathrm{S}$ ), a small portion of the South Pacific until longitudes near South Orkneys and South Georgia $35^{\circ} \mathrm{W}$. (Figure 1). Even females generated more points than males, they generated smaller densities than males, probably indicating they forage in a more dispersed way.

Latitude is not different between genders $\left(\mathrm{F}_{1,166}=0.1\right.$; $\mathrm{P}=0.76)$, but is different in months $\left(\mathrm{F}_{2,166}=0.3 ; \mathrm{P}=0.04\right)$ (Figure 2). No variation of gender latitude usage was detected along the months $\left(\mathrm{F}_{2,166}=0.5 ; \mathrm{P}=0.63\right)$. Longitude is not different between genders $\left(\mathrm{F}_{1,166}=0.05 ; \mathrm{P}=0.83\right)$, nor among months $\left(\mathrm{F}_{2,166}=2.3 ; \mathrm{P}=0.1\right)$ and no variation of gender longitude usage was detected along the months $\left(\mathrm{F}_{2,166}=0.06 ; \mathrm{P}=0.94\right)$.

\section{Discussion}

Our results clearly indicate males forage in more frequency near the colony than females, and as a consequence tend to enhance Kernel density in the areas they are using. On the other hand, females' frequencies are lower along their entire distribution. These are the first results on foraging movements of Antarctic SGPs. Some results are in accordance with studies on South American Giant Petrel populations (González-Solís et al., 2000; Copello et al., 2011). Our study is in accordance with literature which indicates that female frequency is homogeneous along their distribution while males tend to concentrate close to their colonies. But in matters of distribution, our results are in disagreement with those found for South American populations since there are no latitudinal or longitudinal differences between genders. There is a marked difference between male and female distribution between genders in both Giant Petrel species (González-Solís et al., 2000; Copello et al., 2011). Copello et al. (2011) verified a slight difference between southern and northern colonies

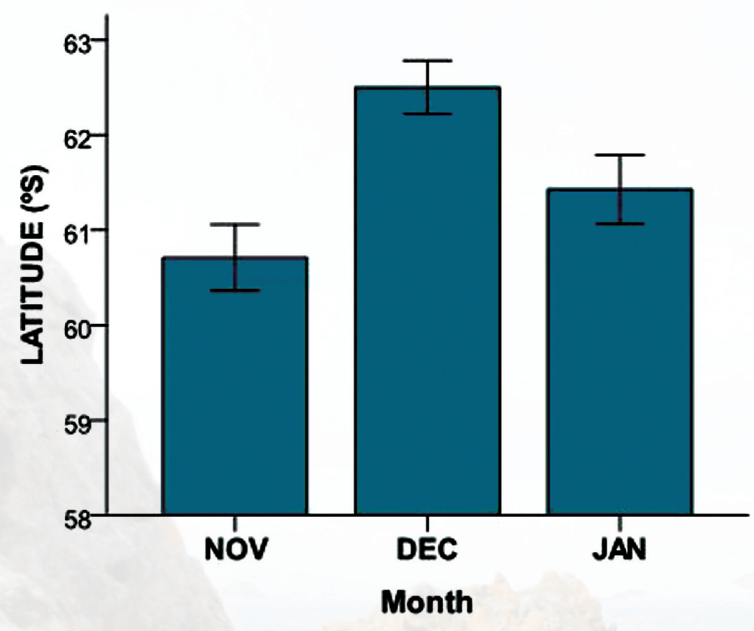

Figure 2. Average latitude used by Southern Giant Petrels in November, December and January in 2011/12 summer. Error bars are standard error.

in Argentina, so, differences in foraging behavior can be attributed to the southern position of Stinker Point population, as a consequence their behavior is different from northern populations. Quintana \& Dell'Arciprete (2002) and Copello et al. (2011) tagged birds in the late incubation period and verified birds remained closer to their colony, while ours showed differences in areas used along the breeding period.

\section{Conclusion}

Males and females range over the same portion of the ocean with a high overlap, which is quite different from literature information. Such differences may be due to a natural geographical variation of the species and because of the period the data was collected. The perspective of including in the analysis variables such as sea temperature and productivity will help us extend our explanations on male-female differences.

\section{Acknowledgements}

This work integrates the National Institute of Science and Technology Antarctic Environmental Research (INCTAPA) that receives scientific and financial support from the National Council for Research and Development (CNPq process: $n^{\circ}$ 574018/2008-5) and Carlos Chagas 
Research Support Foundation of the State of Rio de Janeiro (FAPERJ nº-16/170.023/2008). The authors also acknowledge the support of the Brazilian Ministries of Science, Technology and Innovation (MCTI), of Environment (MMA) and Inter-Ministry Commission for Sea Resources (CIRM).

\section{References}

Adams, J. \& Flora, S. (2010). Correlating seabird movements with ocean winds: linking satellite telemetry with ocean scatterometry. Marine Biology, 157: 915-929.

Copello, S.; Dogliotti, A. I.; Gagliardini, D.A. \& Quintana, F. (2011). Oceanographic and biological landscapes used by the Southern Giant Petrel during the breeding season at the Patagonian Shelf. Marine Biology, 158: 1247-1257.

González-Solís, J.; Croxall, J.P. \& Wood, A.G. (2000). Foraging partitioning between Giant Petrels Macronectes spp. and its relation with breeding population changes at Bird Island, South Georgia. Marine Ecology Progress Series, 204: $279-288$.

Harris, C.M.; Carr, R.; Lorenz, K.\& Jones, S.(2011). Important Bird Areas in Antarctica: Antarctic Peninsula, South Shetland Islands, South Orkney Islands - Final Report. Cambridge: Environmental Research \& Assessment Ltd.

Mallory, M.L.; Gaston, A.J.; Forbes, M.R. \& Gilchrist, H.G. (2009). Influence of weather on reproductive success of northern fulmars in the Canadian High Arctic. Polar Biology, 32:529-538.

Quintana, F. \& Dell'Arciprete, O.P. (2002). Foraging grounds of Southern Giant Petrels (Macronectes giganteus) on the Patagonian Shelf. Polar Biology, 25: 159-161.

Rolland, V.; Weimerskirch, H. \& Barbraud, C. (2010). Relative influence of fisheries and climate on the demography of four albatross species. Global Change Biology,16: 1910-1922.

Sandvik, H.; Coulson, T. \& Saether, B.E. (2008). A latitudinal gradient in climate effects on seabird demography: results from interspecific analysis. Global Change Biology, 14: 703-713. 